\title{
Status Report on the NuScale Module Developed in the Modelica Framework
}

\author{
Konor Frick
}

August 2019

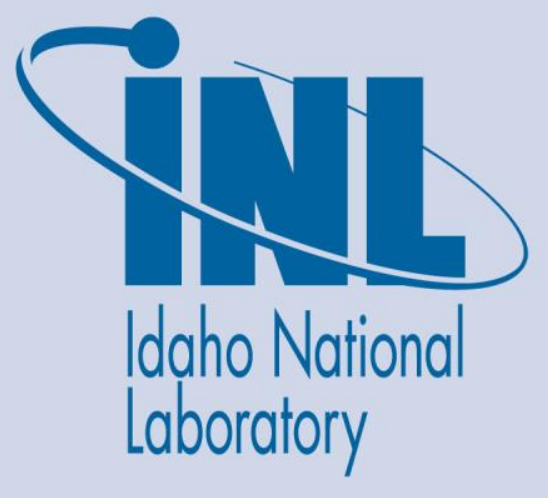

The INL is a U.S. Department of Energy National Laboratory operated by Battelle Energy Alliance 


\section{DISCLAIMER}

This information was prepared as an account of work sponsored by an agency of the U.S. Government. Neither the U.S. Government nor any agency thereof, nor any of their employees, makes any warranty, expressed or implied, or assumes any legal liability or responsibility for the accuracy, completeness, or usefulness, of any information, apparatus, product, or process disclosed, or represents that its use would not infringe privately owned rights. References herein to any specific commercial product, process, or service by trade name, trade mark, manufacturer, or otherwise, does not necessarily constitute or imply its endorsement, recommendation, or favoring by the U.S. Government or any agency thereof. The views and opinions of authors expressed herein do not necessarily state or reflect those of the U.S. Government or any agency thereof. 
INL/EXT-19-55520

Revision 0

\title{
Status Report on the NuScale Module Developed in the Modelica Framework
}

August 2019

Idaho National Laboratory Idaho Falls, Idaho 83415

http://www.inl.gov

\author{
Prepared for the \\ U.S. Department of Energy \\ Office of Nuclear Energy \\ Under DOE Idaho Operations Office \\ Contract DE-AC07-05ID14517
}





\section{ABSTRACT}

This report provides a status update on development of the NuScale reactor model in the Modelica framework.

Current model development has led to the creation of a dynamic NuScale module in the Modelica language that operates under natural circulation and is consistent with design parameters set forth in the design certification documentation for the Nuclear Regulatory Commission. Controllers have been developed that are consistent with controllers mentioned by NuScale and similar pressurized water reactor systems. Simulation results demonstrate the capability of these controllers to properly maintain their target parameters while preserving system values within reasonable bounds.

Through commencement of this work, the first generation of NuScale model in the Modelica M\&S framework has been completed. This first generation is capable of recreating nominal design values laid forth in the public literature and accommodating transients down to $60 \%$ power. Future generations of the model will incorporate finer tuning on controllers to reduce oscillations seen with steam offtake and will include a more rigorous representation of components described in the future work section. 


\section{CONTENTS}

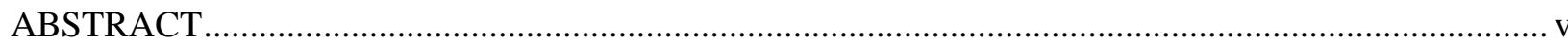

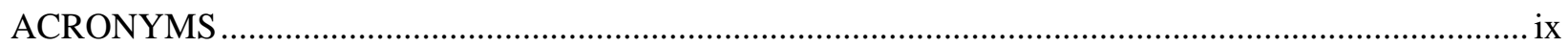

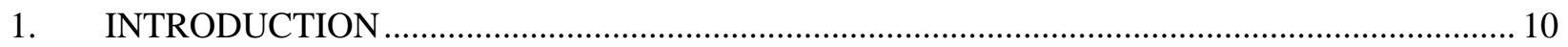

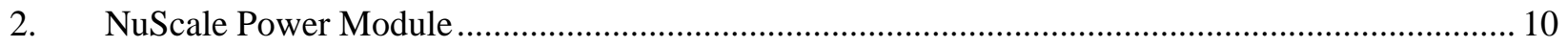

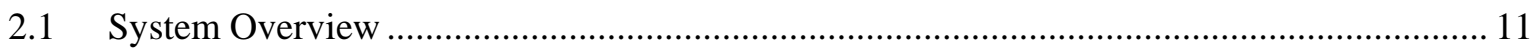

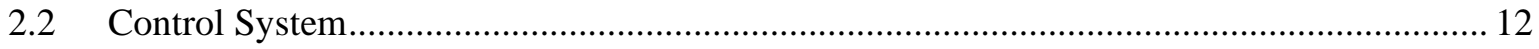

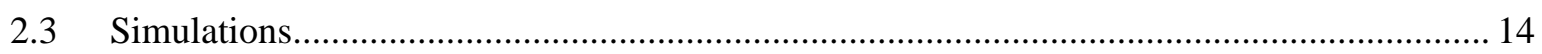

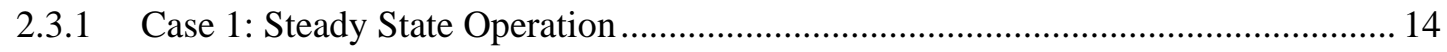

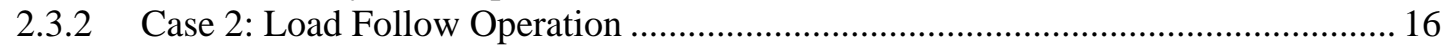

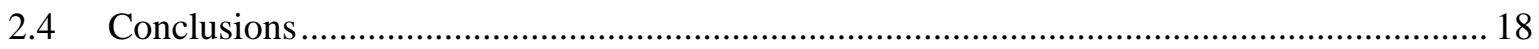

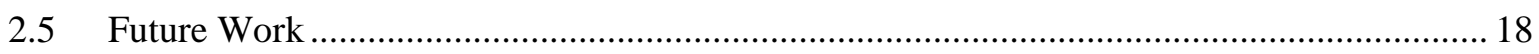

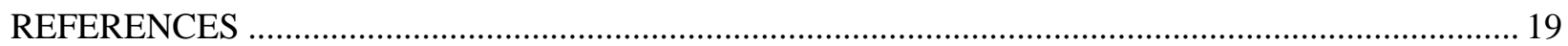




\section{FIGURES}

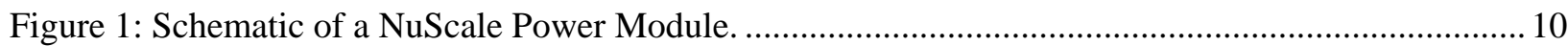

Figure 2: Overall NuScale Reactor from vessel to power generation.................................................... 11

Figure 3: Modelica Representation of the NuScale Module.................................................................. 12

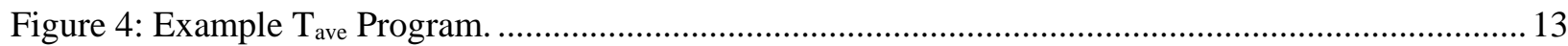

Figure 5: Primary Side Control: $\mathrm{T}_{\text {ave }}$ program and FeedPump Controllers implemented......................... 13

Figure 6: Secondary Side Control: Turbine Control Valve and Turbine Bypass Valves

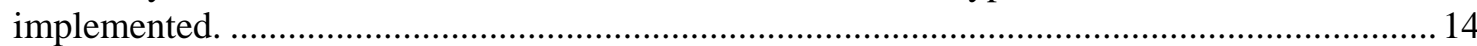

Figure 7: Steady State Simulation Results for: a) Reactor thermal power, b) Steam generator pressure, c) Turbine Output, d) Primary System Average Temperature.

Figure 8: Steady State Simulations continued for: e) Primary side mass flow, f) Steam generator exit temperature, g) Secondary side mass flow, h) Primary pressure.

Figure 9: Dynamic Simulation results for: a) Reactor thermal power, b) Steam generator pressure, c) Turbine Output, d) Primary System Average Temperature

Figure 10: Dynamic Simulations continued for: e) Primary side mass flow, f) Steam generator exit temperature, g) Secondary side mass flow, h) Primary pressure. 


\section{ACRONYMS}

Dymola Dynamic Modeling Laboratory

EM Energy Manifold

INL Idaho National Laboratory

IPWR Integral Pressurized Water Reactor

JUMP Joint Use Modular Plant

LOCA Loss of Coolant Accident

LWR Light Water Reactor

M\&S Modeling and Simulation

NRC Nuclear Regulatory Commission

N-R IES Nuclear-renewable Integrated Energy System

N-R HES Nuclear-renewable Hybrid Energy System

PHS Primary Heat System

UAMPS Utah Associated Municipal Power Systems 


\section{INTRODUCTION}

This report summarizes the current status on the component models developed in the Modelica framework at Idaho National Laboratory (INL) under the Nuclear-Renewable Integrated Energy Systems (N-R IES) program, previously defined as the Nuclear-Renewable Hybrid Energy Systems (N-R HES) program. In Fiscal Year (FY 2019) INL identified a need for further development of advanced nuclear reactor models within the N-R IES program. This need was further intensified with initiation of the Joint Use Modular Plant (JUMP) program at INL, which is a partnership among INL, NuScale, and the Utah Associated Municipal Power Systems (UAMPS).

The models were implemented using the commercially available Modelica-based Modeling and Simulation (M\&S) environment, i.e., a Dynamic Modeling Laboratory (Dymola) version 2019 FD01 [1]. In-house developed packages and open-source libraries were utilized to facilitate M\&S. In particular, the Modelica standard library version 3.2.2 [2] and TRANSFORM [3] from Oak Ridge National Laboratory were utilized.

\section{NuScale Power Module}

Utilizing data from the 2018 Nuclear Regulatory Commission (NRC) design certification application $[4,5,6]$ a detailed NuScale module, as illustrated in Figure 1, was created inside the Modelica language.

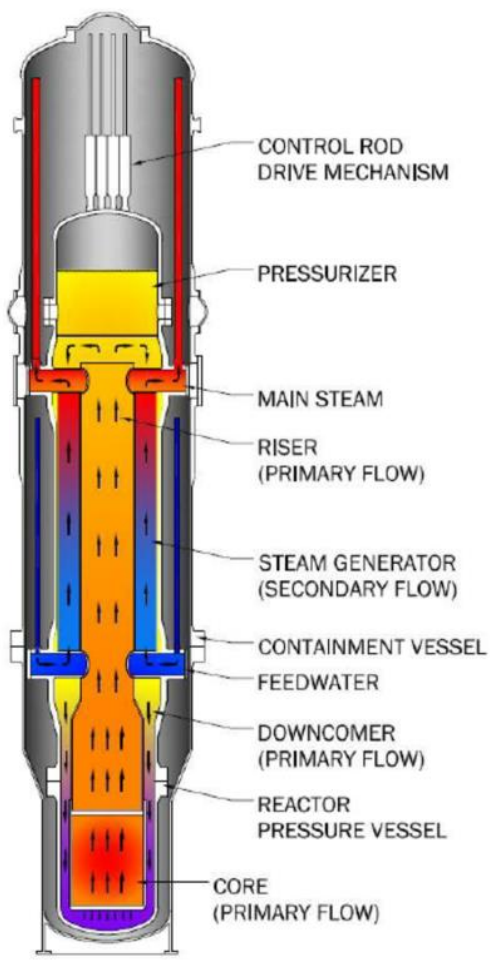

Figure 1: Schematic of a NuScale Power Module. 


\subsection{System Overview}

The NuScale power module is an integral pressurized water reactor (IPWR) that operates with a nominal thermal power of $160 \mathrm{MWt}$ capable of producing $50 \mathrm{MWe}$ to the electric grid. Integral designs are fully self-contained, eliminating the need for large main steam lines that can potentially lead to large break loss of coolant accidents (LOCA). Instead the primary system has only an inlet of feed water into the bottom of the helical coil steam generator and an exit point for steam at the top of the steam generator as depicted in Figure 1. The primary system does not include any pumps but instead operates under natural circulation. Natural circulation reactors rely on the height and density differentials between hot and cold water to drive circulation of water through the core. Through elimination of primary coolant pumps an entire class of accident scenarios is eliminated. Modeling efforts in this report focused on three main efforts: matching thermal and electric output, matching system geometry, and matching natural circulation efforts in the system via flow rates and temperature differentials.

The primary side of the module has heights and cross sectional areas in accordance with NRC design certification material. The primary and secondary sides were modeled in their entirety as shown in Figure 2 and Figure 3. The helical coil steam generator was modeled as a once through steam generator where the secondary side is on the inside of the tubes and the primary side fluid run along the outside of the tubes.

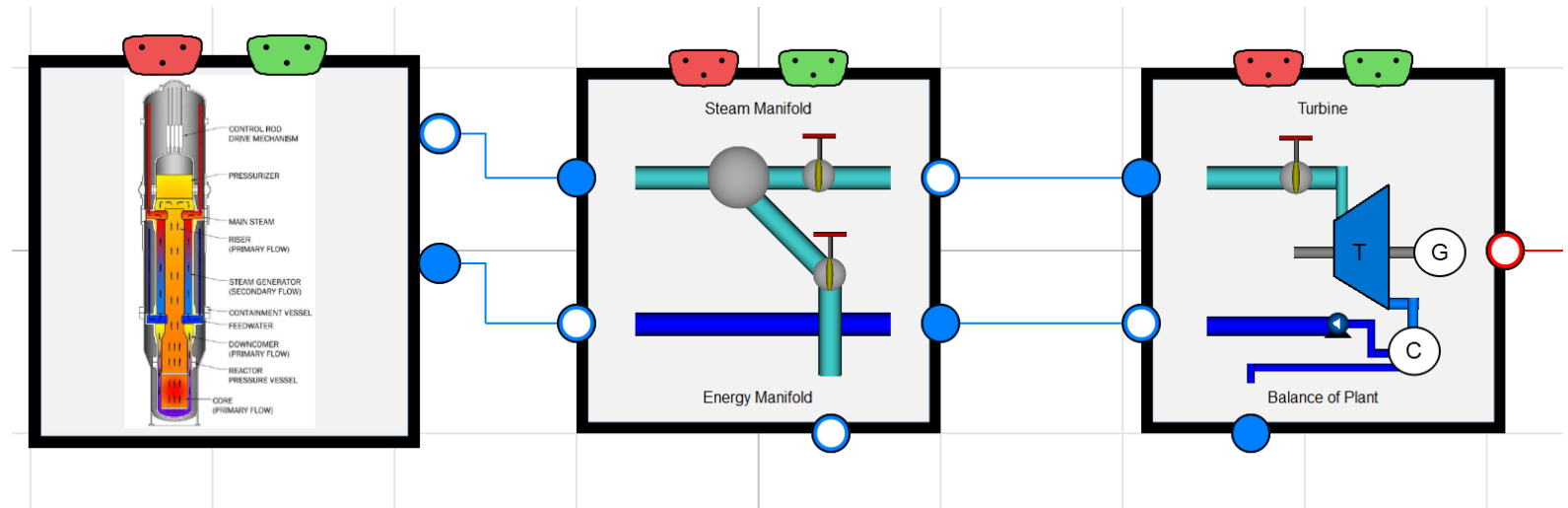

Figure 2: Overall NuScale Reactor from vessel to power generation.

Following the steam generator is a steam manifold. The steam manifold is modeled simply as piping being directed from the nuclear reactor to the turbine. The manifold is used to direct flow to the turbine and can be used to bypass steam off the main steam line into " $n$ " number of industrial processes. The balance of plant model is developed to a fidelity level that is capable of including standard balance of plant control algorithms (e.g. turbine control valves and turbine bypass valves.). The turbine generator set was not modeled to a level of fidelity consistent with the primary system for two reasons.

1. The particular choice of turbine generator set is not fully fleshed out with NuScale as of yet, meaning the balance of plant would need to be continually updated as components shift.

2. Reactor specific transients on power, pressure, etc. do not come from the particular choice of balance of plant but rather from the control systems utilized to operate it.

The balance of plant model can be improved as the balance of plant on the NuScale reactor module becomes further substantiated. 


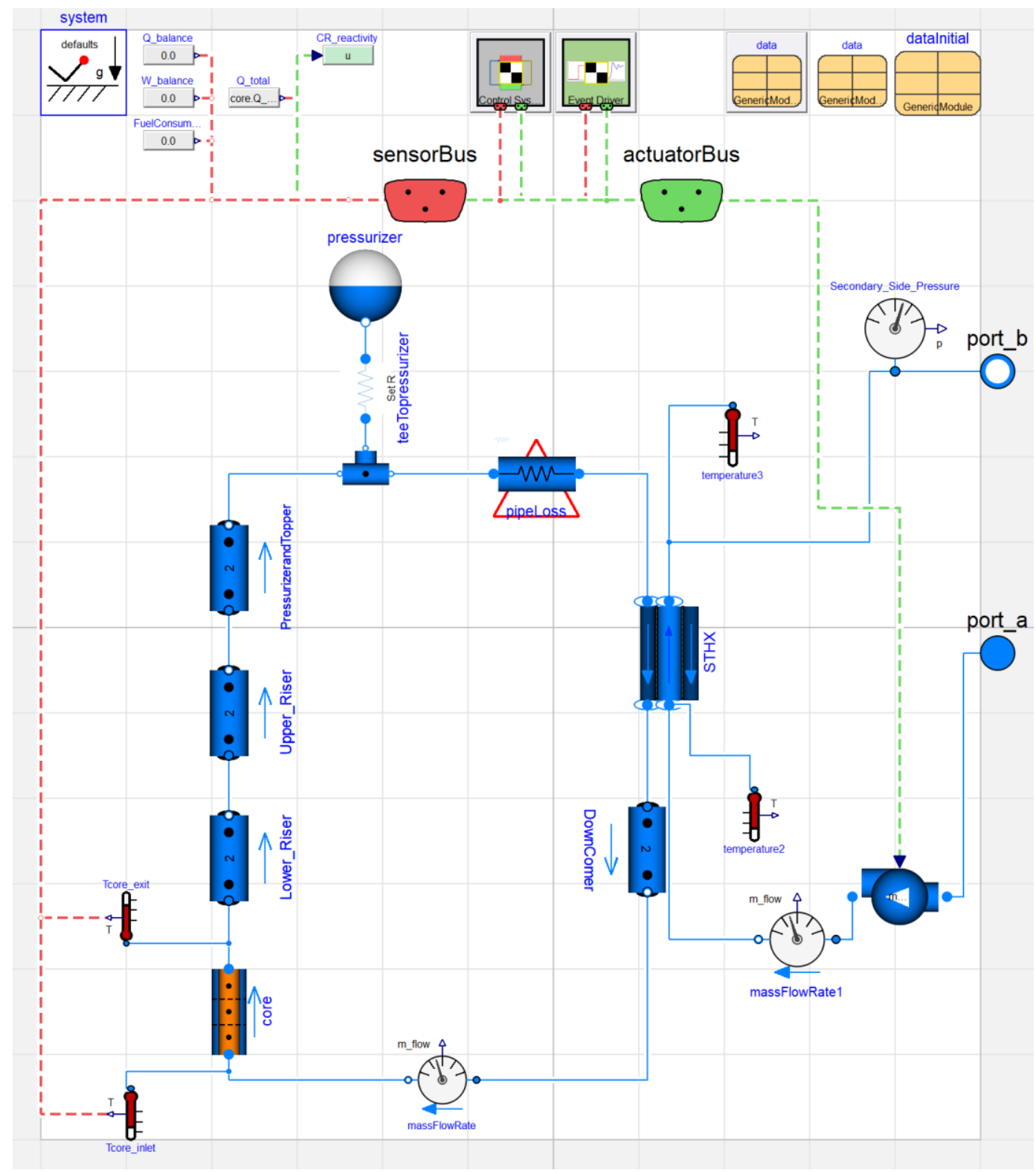

Figure 3: Modelica Representation of the NuScale Module.

\subsection{Control System}

The control system implemented in the NuScale module is similar to a standard 4-loop U-tube steam generator. The turbine control valve modulates to regulate turbine power to meet demand. The control rods move in and out of the core to maintain a specified $\mathrm{T}_{\text {ave }}$ program, similar to the one seen in Figure 4 . Then feed flow is oscillated to maintain a specified calorimetric enthalpy at the exit of the helical steam generator. Steam generator pressure is indirectly controlled via a combination of the primary system average coolant temperature, turbine control valve position, and turbine bypass valve position. In load follow operation the turbine bypass valve modulates to allow excess steam energy that is not needed by the turbine to go directly to the condenser. This control algorithm maintains constant reactor power. 


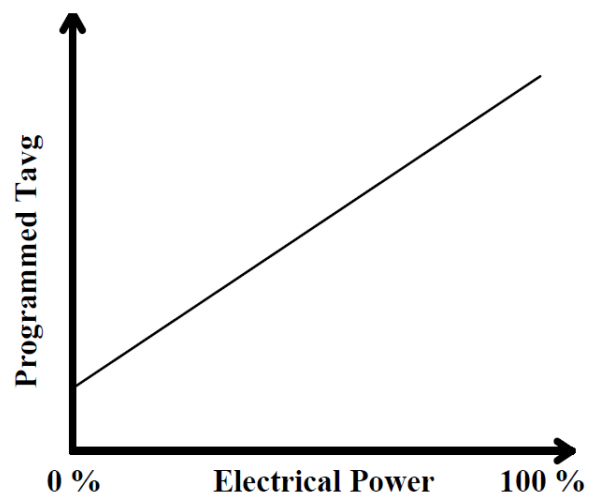

Figure 4: Example $\mathrm{T}_{\text {ave }}$ Program.

Illustrated in Figure 5 is the control system utilized for the primary side of the reactor. Included within it is the $T_{\text {ave }}$ program that modulates the control rods in and out of the core to maintain a preset average temperature on the primary side of the reactor.

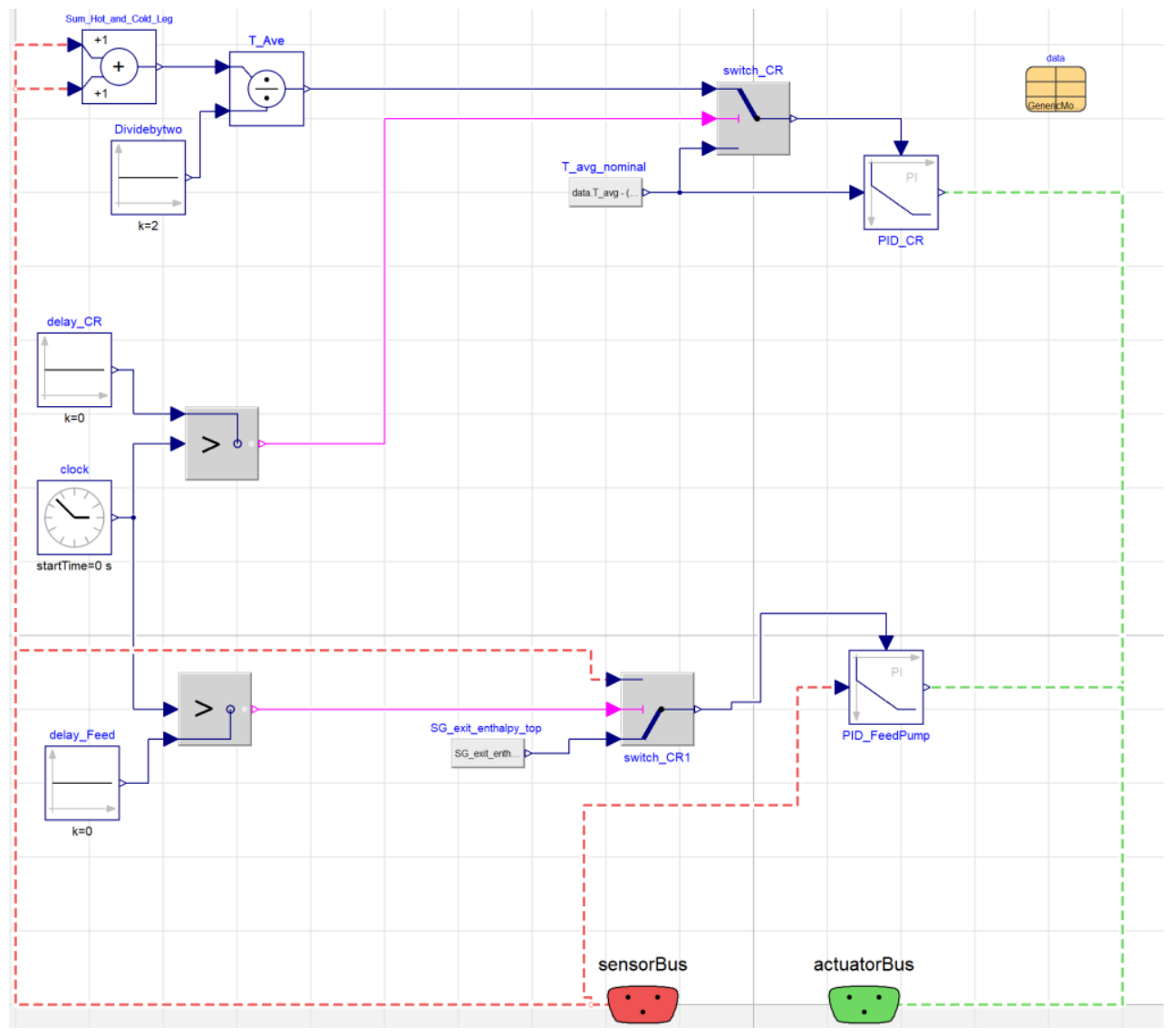

Figure 5: Primary Side Control: $\mathrm{T}_{\text {ave }}$ program and FeedPump Controllers implemented. 
The secondary side control strategy is shown in Figure 6. Controllers oscillate the turbine control valve to meet turbine demand and the turbine bypass valve to maintain nominal reactor power.

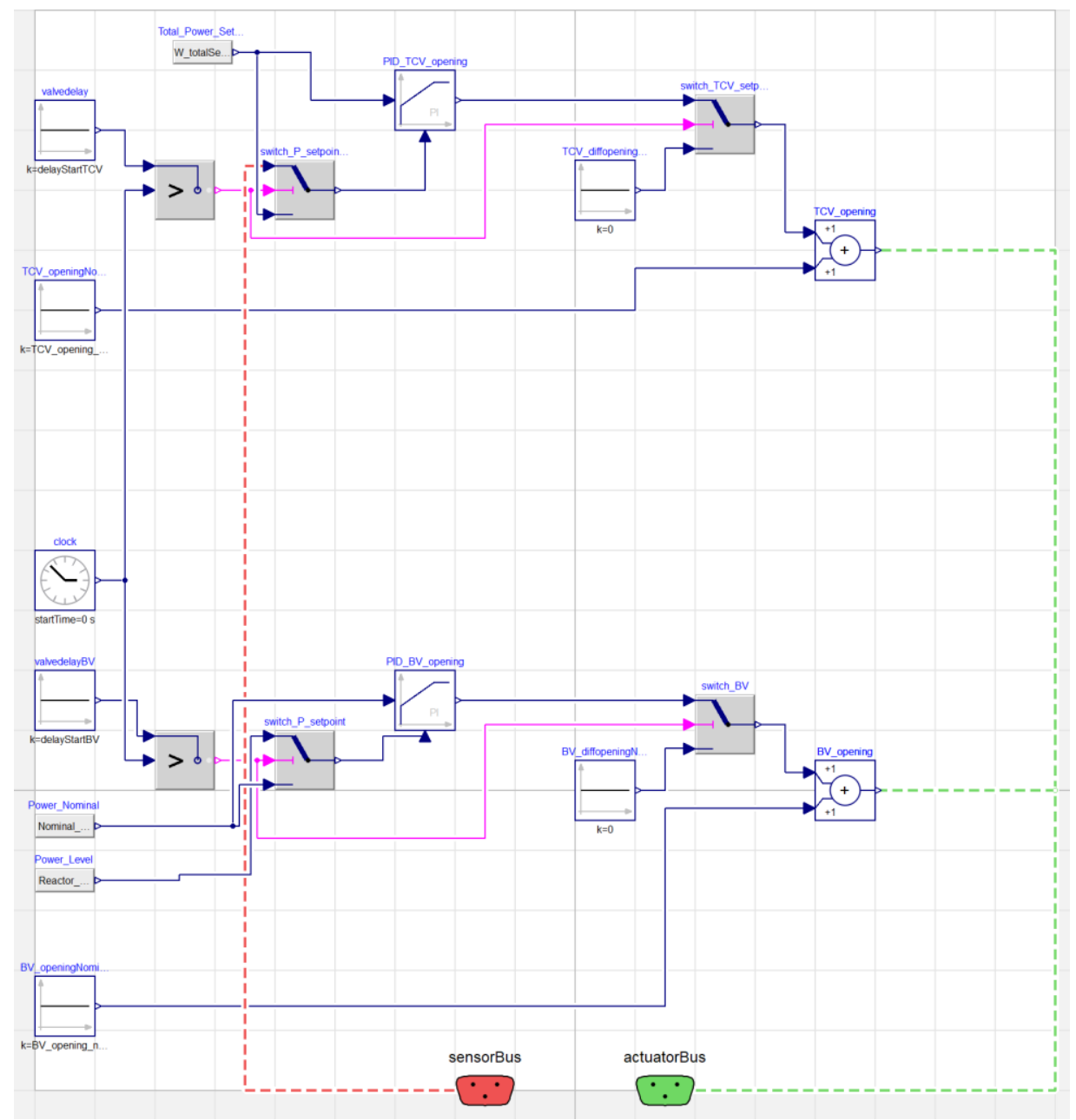

Figure 6: Secondary Side Control: Turbine Control Valve and Turbine Bypass Valves implemented.

\subsection{Simulations}

Two case studies were conducted to showcase the current status of the NuScale reactor in Dymola. One is a null transient to show that the plant is capable of reproducing state points consistent with reference values from the design applications and the second is a dynamic simulation to show the load following capability of the reactor when subjected to the control schemes implemented.

\subsubsection{Case 1: Steady State Operation}

In steady state operation the ability of the controllers to move from the initial conditions to the steady state values designated in the design certification can be seen. At time zero the initial conditions provided to the system were solved, giving all of the solution variables. Once this was completed the control systems began to move the initial solution to the nominal operating conditions set forth in the controllers. Primary system average temperature is initially too high, meaning reactivity was inserted into the core via a combination of control rod movement and boron concentration thus causing a power decrease in the core. 
Turbine output is initially too low, therefore the turbine control valve oscillates to increase steam flow to the turbine and thereby increase turbine output.

Steam generator pressure is indirectly controlled and initially oscillates between 34.2 and 36 bar [496 psia -522 psia] before settling at 34.6 bar [501.8 psia] at about the 1.5 hour mark. This value corresponds with the nominal secondary side pressure set forth in Chapter 10 of the design certification manual [ref 10]. Reactor power eventually settles at $160.3 \mathrm{MWt}$ at the same 1.5 hour mark.
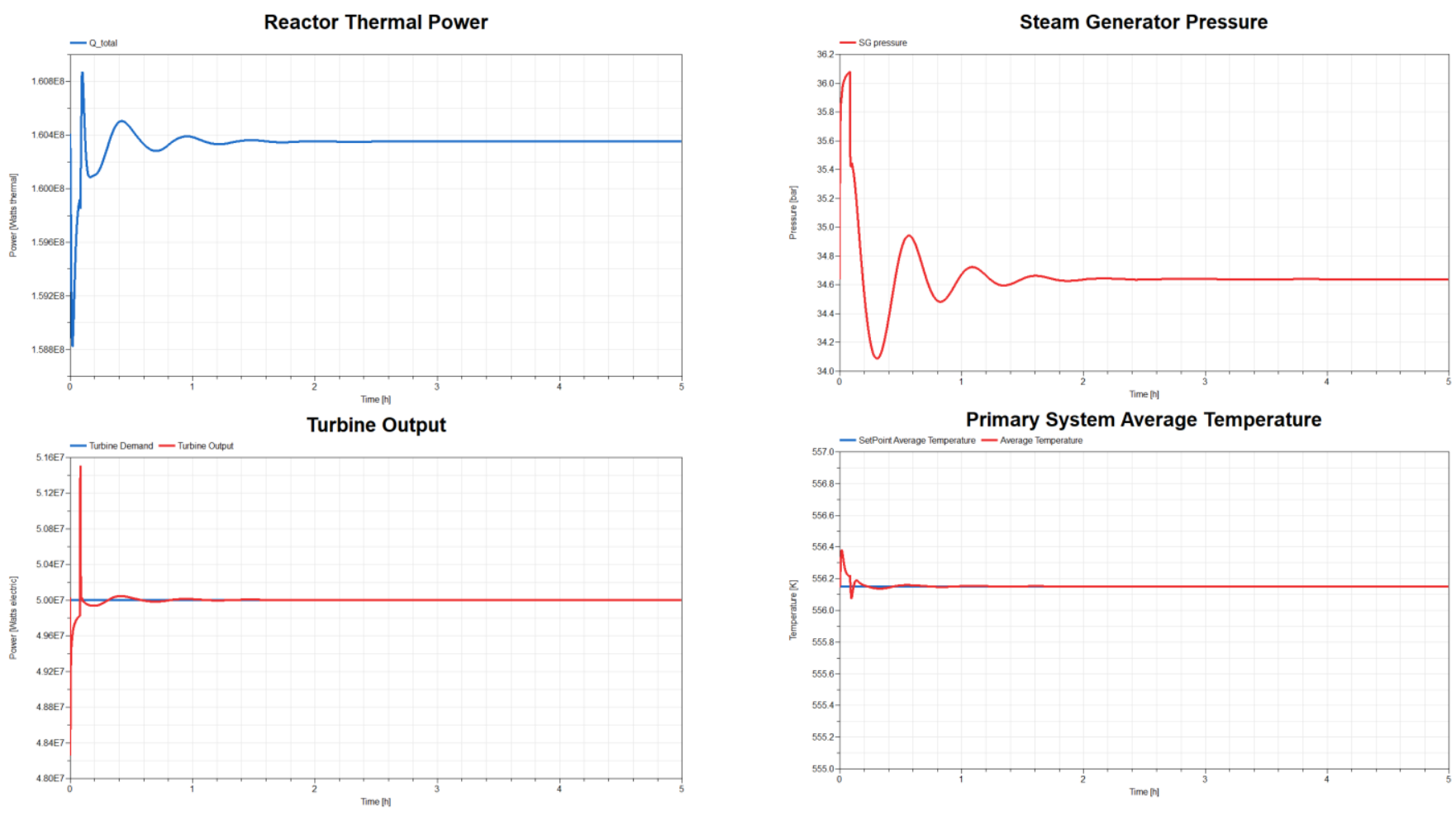

Figure 7: Steady State Simulation Results for: a) Reactor thermal power, b) Steam generator pressure, c) Turbine Output, d) Primary System Average Temperature.

Steam generator exit temperature settles at a value of $580.9 \mathrm{~K}\left[585.95{ }^{\circ} \mathrm{F}\right]$ which corresponds to approximately $118^{\circ} \mathrm{F}$ of superheat. Secondary side mass flow rate settles at a rate of $67.6 \mathrm{~kg} / \mathrm{sec}$ $[536,500 \mathrm{lbm} / \mathrm{hr}]$. This is $0.8 \%$ more flow than the quoted best estimate in the certification documentation. Primary Pressure settles to $127.6 \mathrm{bar}$ [1851 psia] and a primary mass flow of $561.7 \mathrm{~kg} / \mathrm{sec}$ [4.458e $6 \mathrm{lbm} / \mathrm{hr}$ ] which is a $4.6 \%$ lower flow rate than the nominal value considered in the NuScale design. This differential, while relatively small, can be attributed differences in friction factors, exact geometric orientations, and steam tables used. 

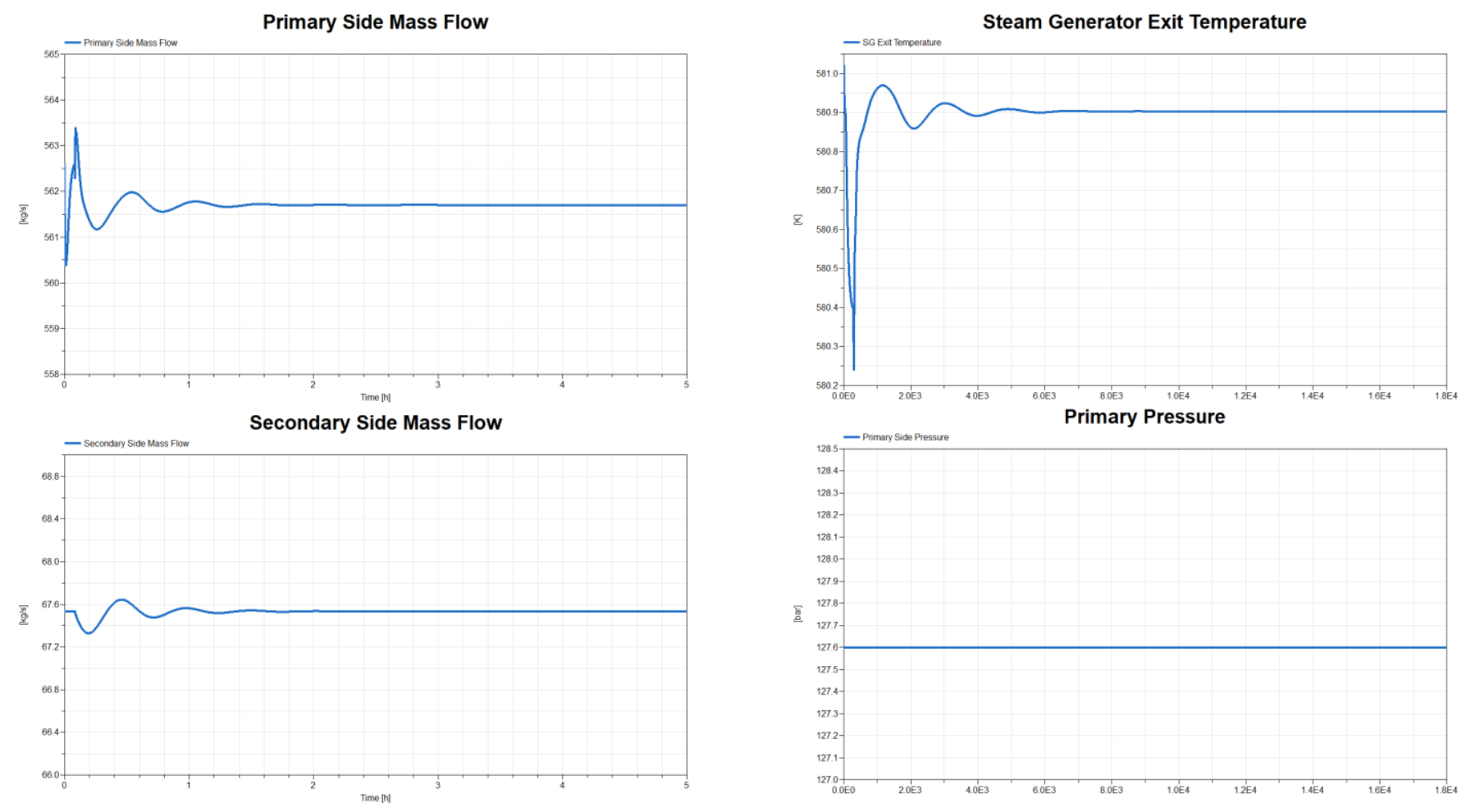

Figure 8: Steady State Simulations continued for: e) Primary side mass flow, f) Steam generator exit temperature, g) Secondary side mass flow, h) Primary pressure.

\subsubsection{Case 2: Load Follow Operation}

To test the control schemes and the system response to transient simulations a five hour simulation was conducted that initially started at nominal conditions. Initially, the system is moving to those conditions for initialization purposes. Then, at hour 1, a two-hour ramp down in power from $100 \%$ to $60 \%$ was conducted. System valving and control systems were able to meet this ramp speed with minor oscillations in system pressure, and primary system average temperature. Illustrations of these oscillations are shown in Figure 9 and Figure 10.

Reactor Thermal power is able to be maintained constant throughout the transient by utilizing the turbine bypass valve to dump excess steam directly to the condenser. Following the first hour when the code is initializing, the steam generator pressure is maintained in a band between 33.5 bar and 35.2 bar [ 485 psia - 510.3 psia]. Following initialization the primary system average temperature is maintained at a constant value throughout the five hour transient. The feed pump at the bottom of the steam generator is able to properly oscillate secondary side mass flow to maintain steam generator exit temperature at $581 \mathrm{~K}$ $\left[585^{\circ} \mathrm{F}\right]$. 

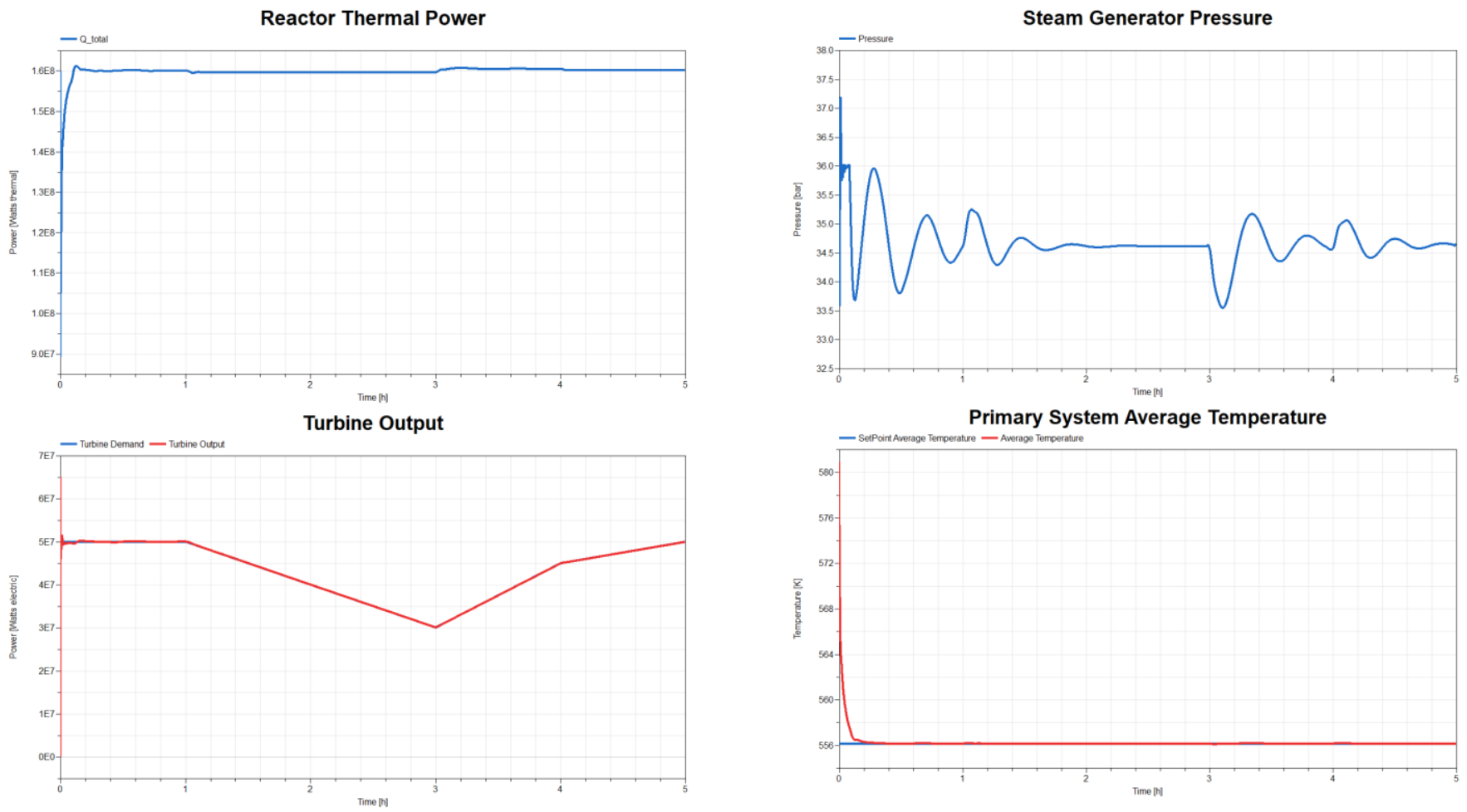

Figure 9: Dynamic Simulation results for: a) Reactor thermal power, b) Steam generator pressure, c) Turbine Output, d) Primary System Average Temperature.
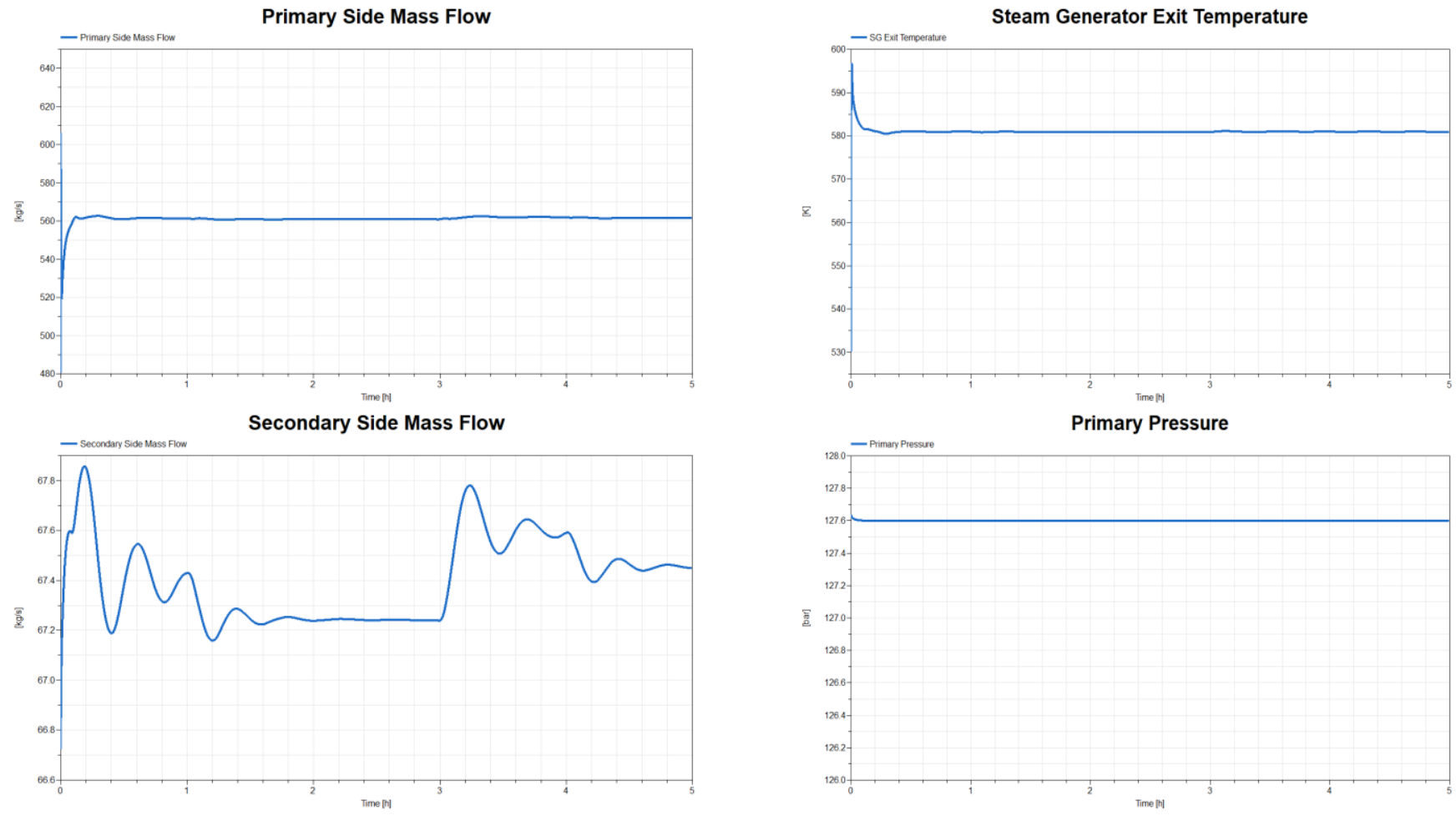

Figure 10: Dynamic Simulations continued for: e) Primary side mass flow, f) Steam generator exit temperature, g) Secondary side mass flow, h) Primary pressure. 


\subsection{Conclusions}

Current model development has led to the creation of a dynamic NuScale module in the Modelica language that operates under natural circulation and is consistent with design parameters set forth in the design certification documentation. Controllers have been developed that are consistent with controllers mentioned by NuScale and similar pressurized water reactor systems. Simulation results demonstrate the capability of said controllers to properly maintain their target parameters while preserving system values within reasonable bounds.

Through commencement of this work, the first generation NuScale model in the Modelica M\&S framework has been completed. This first generation is capable of recreating nominal design values laid forth in the public literature and accommodating transients down to $60 \%$ power. Future generations of the

model will incorporate finer tuning on controllers to reduce oscillations seen with steam offtake and will include a more rigorous representation of components described in the future work section.

\subsection{Future Work}

Initial work has allowed for the completion of a first generation NuScale module that incorporates natural circulation, control systems, reactivity feedback, and matches nominal operating conditions outlined in design certifications. A higher fidelity model, as will be necessary to support the JUMP program, will require the following upgrades:

1. Complete a power uprate to $200 \mathrm{MWt}$ and $60 \mathrm{MWe}$ as has been announced by NuScale.

2. Subject the system to a wider array of transient scenarios to allow for better controller tuning.

3. Update the steam generator system to be consistent with NuScale data.

4. Implement all of the NuScale specific reactivity feedback coefficients.

5. Allow for cycle burnup and input of soluble boron at beginning, middle, and end of cycle.

6. Update the turbine generator set once a design is selected by NuScale.

7. Include off-design controllers for accident scenarios.

Upgrades 1-7 can be made for a public facing version of the model; however, these upgrades will likely diverge from a future proprietary version of the model that will be needed to support some future analysis activities. Many of the values required to properly upgrade power, controllers, materials, tube lengths, and operating scenarios are proprietary to NuScale. 


\section{REFERENCES}

[1] Dassault Systems. DYMOLA Systems Engineering [Internet]. [updated 2018 May 2; cited 2018 May 16]. Available: https://www.3ds.com/products services/catia/products/dymola/.

[2] Modelica Association. Modelica Standard Library [Internet]. [updated 2018 May 22; cited 2018 May 16]. Available: https://github.com/modelica/Modelica.

[3] Greenwood, M. S.: TRANSFORM - TRANsient Simulation Framework of Reconfigurable Models. Computer Software. https://github.com/ORNL-Modelica/TRANSFORM-Library. 07 Nov. 2017. Web. Oak Ridge National Laboratory. doi:10.11578/dc.20171109.1. Available: https://github.com/ORNL-Modelica/TRANSFORM-Library

[4] NuScale. NuScale Standard Plant Design Certification Application-Chapter Four: Reactor-Part 2Tier 2. Revision 2. October 2018.

[5] NuScale. NuScale Standard Plant Design Certification Application-Chapter Seven: Instrumentation and Controls-Part 2- Tier 2. Revision 2. October 2018.

[6] NuScale. NuScale Standard Plant Design Certification Application-Chapter Ten: Steam and Power Conversion System-Part 2- Tier 2. Revision 2. October 2018. 